\title{
Coping Strategies Adopted by Urban Poor to Ameliorate Food Insecurity: Case of United States, Belize and India
}

\author{
Lauri Wright ${ }^{1, *}$, Palak Gupta ${ }^{2}$ \\ ${ }^{1}$ Department of Community and Family Health, College of Public Health, University of South Florida, Tampa, Florida, USA \\ ${ }^{2}$ Department of Food and Nutrition, Lady Irwin College, University of Delhi, Delhi, India \\ *Corresponding author: lwrigh10@health.usf.edu
}

Received April 06, 2015; Revised April 25, 2015; Accepted May 08, 2015

\begin{abstract}
Present research was conducted to understand the coping strategies adopted by urban poor in threecountries: The United States (US), Belize and India. Additionally, the coping strategies were classified into those common to the three countries and those which were unique to a particular country as well. Research was crosssectional based on convenience sampling of families receiving care at selected health centers and clinics. Total sample size was 219 (US, $n=53$, Belize, $n=61$; Indian=105). A semi-structured interview was used to collect data on household food security, coping mechanisms, health status and demography. Additionally, the participants were measured for weight. Standard univariate analysis was conducted using SPSS (version-16).The US had highest prevalence of food insecure families (83\%), followed by Belize (62.3\%), and India (57.1\%). A total of 146 food insecure respondents were interviewed on coping strategies. Common coping strategies adopted by households from all three countries included relying on low-cost cheap foods/seasonal foods, decreasing portion size or number of meals consumed in a day, relying on help from relatives, neighbors and friends during food scarcity, use of resources or savings, pawning, use of government programs, migration of one or more family member, and buying foods on discounts. Strategies unique to a specific country, included praying/ believing in God for help, having back gardens, relying on soup kitchens or religious institutions for food distribution, purchasing food on credit from local grocery shops, starting part-time work to supplement regular employment, freezing food to be consumed during need, and bulk purchase of food items. In conclusion, people were found to adopt coping strategies as an expression of negotiated decisions to minimize the impact of food insecurity. The strategies which are common could be used as foundation to develop interventions to alleviate hunger. Positive, unique strategies could be used to develop interventions which are culturally appropriate, wherever possible.
\end{abstract}

Keywords: food insecurity, coping strategies, hunger, poverty

Cite This Article: Lauri Wright, and Palak Gupta, "Coping Strategies Adopted by Urban Poor to Ameliorate Food Insecurity: Case of United States, Belize and India.” Journal of Food Security, vol. 3, no. 2 (2015): 40-46. doi: 10.12691/jfs-3-2-2.

\section{Introduction}

A household is said to be food secure when food is available at all the times, all people have means to access it, is nutritionally adequate in terms of quantity, quality and variety, and that is acceptable within the given culture [1]. Food security is a major global concern today. One is every eight people in the world (a total of 842 million) in 2011-13, were estimated to be food insecure and suffering from chronic hunger [2]. In 2013, more than one in five U.S. children (21\%) lived in households that were foodinsecure at some point during the year [3]. In India, more than half of the urban slum households were food insecure [4]. In Belize, one-fifth of children under 5 years were stunted; an indicator of chronic undernutrition and hunger [5].

Food insecurity has found to be one of the key factors leading to poor nutrition status - both undernutrition and "overnutrition" [6,7]. There is an extensive literature confirming that food insecurity in developing countries such as India, results in low body weight and stature, especially among young children [8]; and delayed cognitive development [9]. In developed countries such as the United States, chronic food insecurity has been shown to lead to overweight and obesity, especially in women and girls [10], and among older children [11]. Little research has looked at the impact of chronic food insecurity in countries experiencing the nutrition transition. During food insecurity, households adopt certain strategies or plan strategically to minimize its impact [12][13]. It is important to understand these strategies so as to identify what is being done at household or micro-level and how the communities cope up with the situations of food insecurity. Reference [14] divided individual behaviors adopted to manage from food insecurity into four categories: dietary changes, increasing short term availability of food, decrease number of people and rationing strategies. Reference [15] classified coping strategies as less severe, quite severe, severe and very severe strategies. 
The purpose of present research was to understand the coping strategies adopted by urban poor households of three countries: a developed country (United States), a developing country (India), and a country in marked transition (Belize). The study also aimed to classify the coping strategies according to the common themes emerging out of three different countries, cull out the unique practices utilized to alleviate food insecurity and assess their impact on health and well-being.

\section{Methodology}

\subsection{Study Background}

The study was conducted in three countries - United States of America, Belize and India. The countries were purposely selected based on development status and the ease of data collection. One urban poor community was selected from each country. The communities chosen had a high degree of poverty and lacked infrastructure such as proper housing, education or healthcare. The communities or slums were selected per convenience sampling and according to the ease of entry and data collection. The communities selected were: (a) In the US, a poor community in Saint Petersburg, Florida $(n=53)$, (b) In Belize, a poor town in the Cayo District ( $\mathrm{n}=61$ ); and (c) In India, a slum from most vulnerable district of Delhi, i.e., North East Delhi (n=105).

\subsection{Study respondents}

To assess the food security level and coping mechanisms used by food insecure families, a crosssectional, convenience sample of families receiving care at health centers and clinics was selected. The key respondents were women in child bearing age (18-45 years) who were responsible for food procurement and preparation in the household [16].In case women were unavailable; the information was sought from the head of the households which were men in most of the cases. The respondents who agreed to be part of the study and gave written consent were included as the sample.

\subsection{Data Collection}

Data was collected by the principle investigators and graduate students trained on the data collection methods. A Semi-structured interview was used in the study, consisting of questions on: 1) household food security; 2) food insecurity coping mechanisms; 3) health and weight status and demographic information.

1. Household Food Security: Short form six-item scale developed by Blumberg et al (1999) was used [17]. The sequence of questions that was revised by the U.S. Department of Agriculture (2008) was used in the present study [18]. The schedule for each country was prepared according to their regional language so that it is well understood by the respondents. The respondents, who were food secure, were dropped from the study. Only food insecure respondents were questioned about subsequent questions on coping strategies.

2. Food Insecurity Coping Strategies: The Coping Strategies Index (CSI) was used as a qualitative tool to determine food insecurity coping strategies [14]. When using CSI as a qualitative tool, Participatory Rapid Appraisal methods were applied to construct the locally relevant coping strategies. First, generic list of coping behaviors was asked from the CSI Field Methods Manual which classified strategies into 4 general categories - dietary change, increase food availability, decrease number of people, and rationing. Focus group interviews were then conducted with members of the local community to develop a list of location-specific coping behaviors. For each of the 4 general categories, individuals were asked about consumption strategies relevant to the locale.

3. Health and Weight Status and Demographic Information: Participants were asked about the basic demographic information including gender, age, race and ethnicity. Participants were also asked if they had been diagnosed with diabetes, hypertension or heart disease. Anthropometric data included height and weight. Weight was measured using the Omron Full Body Sensor Body Composition Scale, Model HBF-510. Height was self-reported.

\subsection{Ethical Clearance}

Ethical clearance was obtained from the institutional review board in all the three countries. For Unites states, ethical clearance was obtained from University of South Florida. In India, University of Delhi gave ethical clearance; and for Belize, ethical clearance was obtained from Ministry of Health.

\subsection{Data Analysis}

For the study, the data was coded and entered into Microsoft Excel 2010. Various consistency checks were made to eliminate errors while coding and data entry. Both qualitative and quantitative data analysis was done. For the quantitative analysis, standard univariate analysis was done.

1. Household Food Insecurity: The responses of six question of food security scale were coded into binomial category of 0 and 1 , and then summed together. The highest score one could obtain was 6 and lowest being zero. The, households with zero or 1 affirmative response were classified as food secure, those with 2,3 or four affirmative responses were classified as low food secure (LFS), and those with 5 or more affirmative responses were classified as very low food secure (VLFS). The method of analysis was taken from existing reports [18].

2. Coping strategies: Thematic analysis was done [19] to analysis the qualitative data of coping strategies. It is a method to identify, analyze and report themes and patterns of behavior $[19,20]$. The verbatim of the respondents were noted and were used to complement the strategies adopted by them. The strategies were classified using thefour main categories described by coping strategy index dietary change, increase food availability, decrease number of people in the household, and rationing [14]. Further, the common and unique themes for coping with food insecurity were determined. Finally, the strategies were categorized as positive or 
negative based on their impact on health and wellbeing.

3. Anthropometry: Body Mass Index (BMI) was calculated based on the formula weight/height ${ }^{2}$. BMI was classified according to the system used by National Institutes of Health: $18.5-24.9 \mathrm{~kg} / \mathrm{m}^{2}=$ normal weight; $25-29.9 \mathrm{~kg} / \mathrm{m}^{2}=$ overweight; $>30.0$ $\mathrm{kg} / \mathrm{m}^{2}=$ obesity.

\section{Results}

\subsection{Socio-demographic and Anthropometric Data}

A total of 219 individuals participated in the study: 53 in the US, 61 in Belize and 105 in India. In both Belize and the US, 68\% respondents were females. In India, all respondents were females. The mean age of the study respondents were $39 \pm 13.1$ years. In the US, more than half of the respondents were African- American (58.5\%), followed by Caucasian (37.7\%), and Hispanic (4.5\%). In Belize, the majority of respondents were Hispanic (90.2\%), followed by Black (6.5\%) and Caucasian (3.3\%). In India, ethnicity is defined in terms of religion. There was equal distribution among Hindus (45\%) and Muslims (55\%).

In Belize, $45 \%$ of respondents were in the normal BMI category while $55 \%$ who were overweight/ obese. In the US, almost two-third (62.3\%) was overweight or obese; two percent of American respondents were underweight. In India, 65\% of the respondents were normal weight, $12.6 \%$ were overweight or obese and $22.4 \%$ were underweight.

\subsection{Food Security}

According to Figure 1, the sample in the US had the highest prevalence of food insecure families (83\%), of which $41.5 \%$ were VLFS. Belize had second highest food insecurity level (62\%), of which $19.7 \%$ were VLFS. India had more than half households as food insecure (57\%), from which one-fourth (25.7\%) were VLFS.

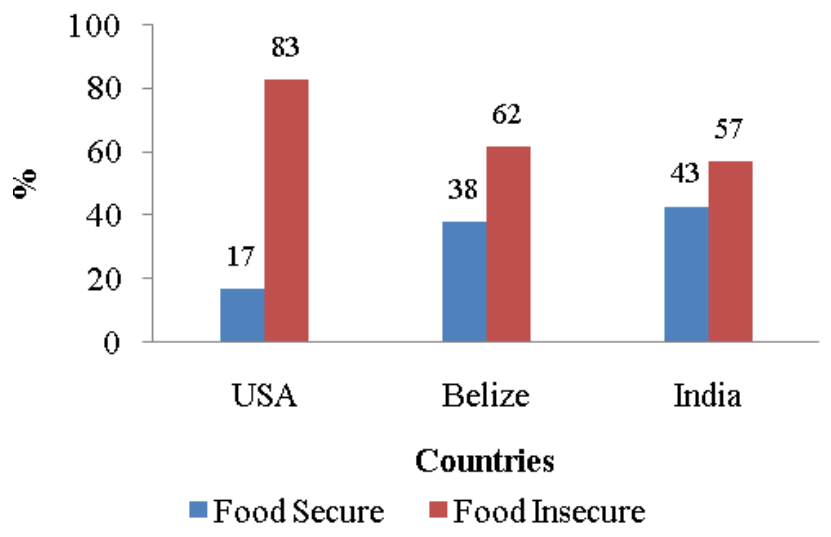

Figure 1. Prevalence of food security in the three counties

\subsection{Coping Strategies}

For the coping strategies, only food insecure families were asked about the strategies adopted by them during food insecure situations. The number of respondents which were asked about coping strategies was 38 from Belize (Table 1), 44 from US (Table 2) and 60 from India (Table 3). The strategies were classified into the CSl's four categories, whether they were unique or common to the other countries surveyed and whether they were positive or negative based on their impact on health and well-being.

Table 1. Coping strategies in Belize

\begin{tabular}{|c|c|c|c|c|c|}
\hline Coping Strategy & & $\begin{array}{c}\text { TFI (n=38) } \\
\%\end{array}$ & $\begin{array}{c}\text { LFS (n=26) } \\
\%\end{array}$ & $\begin{array}{c}\text { VLFS (n=12) } \\
\%\end{array}$ & Verbatim \\
\hline Dietary changes & & 100.0 & 100.0 & 100.0 & \\
\hline Dense foods & + & 100.0 & 100.0 & 100.0 & \begin{tabular}{|l|} 
"Would like to eat more vegetables and meat but not \\
enough money so we eat more beans and rice."
\end{tabular} \\
\hline Not eating enough/ decrease intake & - & 55.3 & 46.2 & 75.0 & $\begin{array}{l}\text { "Eat smaller meals or skip meals to make food } \\
\text { stretch.” }\end{array}$ \\
\hline Increase food availability & & 89.5 & 84.6 & 100.0 & \\
\hline Pray to god/ Divine (Unique) & - & 71.1 & 73.1 & 66.7 & "I pray to God for enough food" \\
\hline Relative/ pooling of resources & ++ & 78.9 & 80.8 & 75.0 & $\begin{array}{l}\text { "Three generations living together to make enough to } \\
\text { survive. "Family gives food to each other from their } \\
\text { gardens." }\end{array}$ \\
\hline Children sent to work/beg & - & 7.9 & 0.0 & 25.0 & "Children asks people at the store for food" \\
\hline Use saving & + & 13.2 & 15.4 & 8.3 & "I have used savings and borrowed money" \\
\hline Pawn & - & 23.7 & 11.5 & 50.0 & “Sold farm equipment so wouldn’t miss payments.” \\
\hline Back garden (Unique) & ++ & 39.5 & 38.5 & 41.7 & $\begin{array}{l}\text { "Eat fruit from fruit trees" "we have a garden we eat } \\
\text { from" }\end{array}$ \\
\hline Decrease number of people & & 7.9 & 0.0 & 25.0 & \\
\hline Migration & + & 5.3 & 3.8 & 8.3 & $\begin{array}{l}\text { "My daughter works in Belize City and sends money } \\
\text { back to feed the children" "Get help from my } \\
\text { daughter in the States" }\end{array}$ \\
\hline Rationing strategy & & 71.1 & 57.7 & 100.0 & \\
\hline Forgo necessity & + & 47.4 & 42.3 & 58.3 & $\begin{array}{l}\text { "Don't go to the doctor so there is enough money for } \\
\text { food" "Sometimes I have to choose between buying } \\
\text { food and paying for dialysis treatment." }\end{array}$ \\
\hline Bulk food prep & ++ & 13.2 & 19.2 & 0.0 & "Make big pot of beans that lasts for many meals." \\
\hline Discount food & - & 71.1 & 73.1 & 66.7 & $\begin{array}{l}\text { "Buy foods at (farmers) market because it’s cheaper." } \\
\text { "Eat the same foods over and over because its } \\
\text { cheaper." }\end{array}$ \\
\hline
\end{tabular}


Table 2. Coping strategies in US

\begin{tabular}{|c|c|c|c|c|c|}
\hline Coping strategies & & $\begin{array}{c}\text { TFI }(n=44) \\
\%\end{array}$ & $\begin{array}{c}\text { LFS }(\mathbf{n}=22) \\
\%\end{array}$ & $\begin{array}{c}\text { VLFS (n=22) } \\
\%\end{array}$ & Verbatim \\
\hline Dietary changes & + & 100.0 & 100.0 & 100.0 & \\
\hline Dense foods & + & 75.0 & 63.6 & 86.4 & $\begin{array}{l}\text { "Fill up on canned spaghetti, chips, } \\
\text { kool-aid." }\end{array}$ \\
\hline Not eating enough/ decrease intake & - & 45.5 & 13.6 & 77.3 & $\begin{array}{l}\text { "By the end of the month, there just } \\
\text { isn't enough so I don't eat as much" }\end{array}$ \\
\hline Increase food availability & + & 93.2 & 90.9 & 95.5 & \\
\hline Government program & + & 95.5 & 95.5 & 95.5 & $\begin{array}{l}\text { Enrolled in Supplemental Nutrition } \\
\text { Assistance Program }\end{array}$ \\
\hline Food pantry (Unique) & + & 68.2 & 50.0 & 86.4 & $\begin{array}{l}\text { "I go to the church food pantry at the } \\
\text { end of the month" }\end{array}$ \\
\hline Relative/ Pooling of resources & + & 27.3 & 13.6 & 40.9 & $\begin{array}{l}\text { "My neighbor and I cook dinners } \\
\text { together for our families to save money" } \\
\text { "If it weren’t for my sister letting me eat } \\
\text { at her house, I wouldn't make it } \\
\text { sometimes." }\end{array}$ \\
\hline Decrease no of people & + & 6.8 & 4.5 & 9.1 & \\
\hline Migration of one or more family members & + & 6.8 & 4.5 & 9.1 & \\
\hline Rationing strategy & + & 63.6 & 31.8 & 95.5 & \\
\hline Forgo necessity & + & 25.0 & 27.3 & 22.7 & $\begin{array}{l}\text { "Sometimes I have to buy food instead } \\
\text { of medicine." }\end{array}$ \\
\hline Bulk food prep & ++ & 25.0 & 22.7 & 27.3 & $\begin{array}{l}\text { "Make a big pot of pasta that will last } \\
\text { for a couple of days." }\end{array}$ \\
\hline Discount food & + & 84.1 & 77.3 & 90.9 & $\begin{array}{l}\text { "I'd like to buy meat and milk but don't } \\
\text { have the money" }\end{array}$ \\
\hline Freezing (Unique) & ++ & 15.9 & 22.7 & 9.1 & $\begin{array}{l}\text { "Frozen vegetables are cheaper and they } \\
\text { don't go bad" }\end{array}$ \\
\hline Buying in sale or coupons & + & 45.5 & 59.1 & 31.8 & $\begin{array}{l}\text { "Only buy foods that are on sale." "I } \\
\text { shop at the cheaper grocery stores and } \\
\text { dollar stores." }\end{array}$ \\
\hline
\end{tabular}

Table 3. Coping strategies in India

\begin{tabular}{|c|c|c|c|c|c|}
\hline Coping strategies & & $\begin{array}{c}\text { TFI (n=60) } \\
\%\end{array}$ & $\begin{array}{c}\text { LFS (n=33) } \\
\%\end{array}$ & $\begin{array}{c}\text { VLFS (n=27) } \\
\%\end{array}$ & Verbatim \\
\hline Dietary changes & & 100.0 & 100.0 & 100.0 & \\
\hline Limit portion sizes & - & 66.7 & 39.4 & 100 & $\begin{array}{l}\text { "We divide among all even if it is less, rest we } \\
\text { consume water" }\end{array}$ \\
\hline Reduce number of meals in a day & - & 26.7 & 3 & 55.5 & \\
\hline Skip food for entire day & - & 12.1 & 3 & 11.1 & \\
\hline Rely on seasonal or locally available food & + & 100 & 100 & 100 & $\begin{array}{l}\text { "Seasonal foods are cheaper, like bottle gourd in } \\
\text { summers and spinach and fenugreek in winters" }\end{array}$ \\
\hline Increase food availability & + & 83.3 & 78.8 & 88.8 & \\
\hline Borrow food from friend or relatives & + & 43.3 & 15.1 & 29.6 & $\begin{array}{l}\text { "We request neighbors or relatives to give raw or } \\
\text { cooked foods" }\end{array}$ \\
\hline Purchase food on credit (Unique) & + & 83.3 & 78.8 & 88.8 & $\begin{array}{l}\text { "We buy on credit with shopkeepers, and repay } \\
\text { with higher interest" }\end{array}$ \\
\hline Use reserves & + & 15.0 & 9.0 & 22.2 & "Use saved money during time of need" \\
\hline Reliance on government food aid & + & 33.3 & 18.2 & 23.3 & $\begin{array}{l}\text { "We buy raw food at subsidized rates and } \\
\text { sometimes eat food which children get from } \\
\text { anganwadi centers" }\end{array}$ \\
\hline Eat at religious places (Unique) & + & 76.7 & 66.7 & 88.8 & $\begin{array}{l}\text { "Rich people distribute food in temples or mosque, } \\
\text { we sit outside temples and eat what is given" }\end{array}$ \\
\hline Children sent to work/ beg & - & 1.0 & 6.0 & 14.8 & $\begin{array}{l}\text { "Children learn nothing in school. Schools are for } \\
\text { rich people. It is better they work and earn than } \\
\text { wasting their time" }\end{array}$ \\
\hline Liquidation of assets & + & 12.1 & 9.0 & 3.7 & "We don’t have any asset to liquidate" \\
\hline Non-earning member starts to work (Unique) & + & 53.3 & 42.4 & 66.6 & $\begin{array}{l}\text { "Women go to rich homes to work as domestic } \\
\text { help". "Sometimes they work as tailors at home" }\end{array}$ \\
\hline Start part-time work (Unique) & + & 68.3 & 60.6 & 77.7 & \\
\hline Decrease no of people & + & 76.7 & 66.7 & 88.8 & \\
\hline Migration of one or more household member & + & 55.0 & 39.4 & 74.0 & $\begin{array}{l}\text { "Home rents are very high. We send household } \\
\text { members to village and live with other men in } \\
\text { small room, saving on rent" }\end{array}$ \\
\hline Rationing strategy & + & 66.7 & 39.4 & 100 & \\
\hline Restrict adult consumption for children & - & 50.0 & 21.2 & 85.2 & \\
\hline Feed males over females (Unique) & - & 5.0 & 3.0 & 7.4 & $\begin{array}{l}\text { "Males work more and are bread-winner of the } \\
\text { family, thus we give food to them first" }\end{array}$ \\
\hline
\end{tabular}




\subsubsection{Dietary Changes}

All food insecure households in all three countries utilized the dietary changes strategy, including relying on low-cost foods or seasonal foods for consumption. Low cost foods are generally energy dense, high carbohydrate foods such as cereals, millets, and potatoes. In the US, $75 \%$ of food insecure households reported consuming dense foods. One household in Belize noted that they would like to eat more vegetables and meat but do not have enough money so they eat more beans and rice. All households in India reported consuming seasonal vegetables and fruits which were cheaper and nutritious. They also reported buying cheaper cuts of meat which are often discarded by the rich; for instance; paws and intestines for consumption.

There were some households in each of the three countries (55\% in Belize, $45 \%$ in US and 67\% in India) adopting a negative, dietary change strategy; specifically, decreasing their food intake during the period of acute food insecurity. Examples included either decreasing the portion size of the meal or decreasing the number of meals eaten in a day. A few households in India (12\%) reported not eating for entire days in the situation of extreme food insecurity. Of note, these negative strategies were adopted by VLFS families' two times more than LFS families.

\subsubsection{Increase Food Availability}

Within the food availability category, some households in all three countries relied on help from relatives, neighbors and friends during food scarcity. In Belize, respondents said, "three generations live together to make enough to survive" and "family gives food to each other from their back gardens." In the US, respondents reported that, "my neighbor and I cook dinners together for our families to save money", and "if it weren't for my sister letting me eat at her house, I wouldn't make it to eat sometimes". In India, people asked neighbors or relative for raw or cooked food to improve their own food availability. Thus, it could be seen that pooling resources might be an important strategies to ameliorate food insecurity.

A second food availability strategy found in all three countries but with wide variation were food assistance programs. In the US, churches and non-government organizations offer food pantries and soup kitchens (68.2\%). In Belize, a small number of participants reported that churches occasionally provided meals to those in need. In India, food insecure individuals or families sit outside religious institutions such as temples, or in mosque, where people distribute food occasionally (76.7\%). Also on special festivals, the food is prepared by the institutions to be distributed to the poor and needy families.

Other strategies to increase food availability adopted by households in two of the three countries were use of resources or savings (13\% in Belize and $15 \%$ in India), pawning(23\% in Belize), and use of government programs and food aid (96\% in US and 33\% in India).

Pawning to improve the food availability was classified as a negative strategy adopted by households of Belize and US. This made the people fall in the trap of money lenders or they pawn against their property on high interest rates and hence end up losing their property or valuable assets. Some households in India (1\%) and Belize (8\%)sent children to beg, work or steal during the extreme situation of food insecurity but also classified as a negative strategy.

Some unique strategies were found to increase food availability. In Belize, we find that they pray to God in hope and faith that God will help and increase the food availability (71\%). One of the respondent said that "I pray to God for enough food”. Also unique to Belize, $40 \%$ of participants utilized a back garden to increase the food availability of vegetables and fruits. A unique food availability strategy found in India was purchasing food on credit from the small, neighborhood grocery shops. If the shop owners know the individual or family, they give food on credit which is repaid when they get resources (83.3\%). Also in India, employed family members sometimes start part time work along-with their regular employment (53.3\%) or the other adult members (usually females) start working (68.3\%) for money. It should be observed all of these unique practices were classified as positive and were used more by the VLFS households in comparison to LFS households.

\subsubsection{Decrease Number of People}

The strategy adopted under this category by all the three countries was migration of one or more family members or the complete family during the extreme food insecurity. This strategy was used atleast two times more frequently by the VLFS families in comparison to the LFS families. The strategy was used most often in India where people and their families come to work from villages to urban areas as casual labors.

\subsubsection{Rationing Strategy}

Rationing is the final category of coping strategies. It was observed that people forgo necessity or budget in order to improve food security (47.4\% in Belize and 25\% in the US). An individual in Belize said, "I don't go to the doctor so that there is enough money for food". Similar strategy was adopted by the people in the US. One respondent reported that, "Sometimes I have to buy food instead of medicine”. Forgoing medical necessities was classified as a negative strategy.

A positive rationing strategy found was households buying and preparing food in bulk which decreases the overall food cost (13.2\% in Belize, $25 \%$ in the US). However, it should be noted that poor people may not be able to buy food in bulk because they do not have enough money or space to buy or keep the large quantities of food. Another positive rationing strategy found in Belize (71\%) and the US (45.5\%) was purchasing discount foods. An individual in Belize said, "I buy foods at the (farmers) market because it's cheaper." Similar to this, households in the US buy food items on sale or use coupons. As reported by one participant, "I buy only those foods that are on sale" and, "I shop at the cheaper grocery stores and dollar stores.” A unique strategy adopted by $16 \%$ of US households was freezing food items to use later or purchasing frozen foods that are cheaper than their fresh counterpart. As reported by one US household, "frozen vegetables are cheaper and they do not go bad".

In India, people were following negative rationing strategies in order to improve food insecurity. Many households reported that adults restrict consumption so 
that children can eat (50\%). Another negative rationing strategy unique to was feeding males over females (5\%) as males are the often the primary bread-winner of the family and have to work hard; thus, males are perceived as deserving to eat more than females. These strategies were adopted by VLFS family's two-fold times more than LFS families.

\section{Discussion}

Although, the aim of the present study was not to assess prevalence, a large number of respondents (57\%-83\%) were food insecure. Though this prevalence is skewed by a small samples size and location of sampling, it does demonstrate the vulnerability of the urban poor.

Food insecure households adopt many coping strategies with different levels of severity and impact on health and well-being. The strategies adopted by the households in this study were consistent with the findings of several previous studies. Similar strategies have been found in different countries to reduce the severity of food insecurity. Norhasmah et al, 2010; Kempson et al, 2003; Dore et al, 2003 identified households rely on less expensive and less preferred food during the situations of food insecurity [15], $[21,22]$. This strategy could be categorized as positive as households are able to improve the access of food by following this strategy; however, they may compromise the nutritional content of the food. For example, they start consuming energy-dense, cheap foods which can lead to micronutrient deficiencies.

Corbett (1988) reported households reduce number of meals eaten per day as a coping mechanism, which is also found in the present study [23]. This can be classified as a negative strategy as it effects the nutrient intake of an individual and hence their nutritional status. Kabeer (1990) also found out that women cut down on number of meals consumed per day during food insecurity situation [24]. He further indicated that employed members looked for additional jobs to increase their income and purchase more food. This was followed by non-earning members in the household such as women, children and the elderly being drawn into employment. The first strategy stated by Kabeer (1990) could be categorized as negative and second as positive strategy (except when children are drawn to work) [24]. Castaneda et al (2000) and Shariff and Khor (2008) also found that employed members were drawn to more odd jobs during food insecurity in order to increase resources [25,26]. These strategies could be considered positive as they increase the household resources to buy food and thus ameliorate food insecurity. Norhasmah et al (2010) also identified food insecure households following strategies such as restricting consumption of adults to make children eat, feeding working members of households at expense of nonworking members, reducing or skipping meals eaten in a day [15]. These all can be classified as negative strategies since it impacts the health status of an individual. He also noted eating at religious places, sending children to eat elsewhere or with neighbors/ relatives as part of coping strategies of food insecure families. These can be called as positive strategies as households attempt to improve the intake of food without putting them in risky situation. Studies found significant association of food insecure households with borrowing money/food and selling valuable materials [26,27], which is similar to our findings. Norhasmah et al (2010), Mardiharini (2005) and Agbola (2008) identified that households during food insecurity, tended to borrow money from friends and relatives, sell or pawn own assets to get cash and purchase food on credit [15], [13], [28]. Borrowing money from friends or relative could be considered positive but selling or pawning to get money is very negative strategy; this strategy may lead to an immediate solution to decrease food insecurity level but it is not a sustainable approach. In Nigeria, nearly $40 \%$ households reported to have had incurred debts in order to afford food [29]. In Manila, Philippines, poor people borrowed money at high interest rates in order to feed their family, as their daily wage did not cover food, education and utilities [30]. In Orissa, India, the money lenders charge exorbitant interest rates often as high as $50 \%$ per month [31]. These are severe and negative strategies as it forces households to get into the lifelong cycle of payments and re-payments making them further vulnerable and food insecure.

The body composition of the study participants is consistent with the existing literature on the changing face of food insecurity. The hunger-obesity paradox has been describe by Popkin-Barry et al (2012) and is defined as the concurrent presentations of obesity in the food insecure population [32]. One behavior attributed to the hungerobesity paradox includes reliance on low cost but high calorie, "filler" foods such as cereals, beans and potatoes. The United States and Belize had the highest obesity rates in this study, which is consistent with transitions in dietary intake including more processed foods. Interestingly, India may be seeing beginning stages of this transition to the hunger-obesity paradox with $12.6 \%$ of the sample classified as overweight or obese.

Among urban poor, the prices of commodities are high, their daily wages or incomes are low and there are many other needs such as paying for rent, electricity, education, and medical care. This result in reduction of proportion of money spent on food. These conditions may lead to enhanced stress which limits an individual capacity to strategize and respond to situation of food insecurity effectively. As such, the average food insecure individual often employs strategies the compromise their nutritional health and perpetuate the cycle of poverty and food insecurity[33].

Wishik and Van der Vynkt (1976) identified the concept of positive deviants (PDs) [34]. In this model, a small number of families, despite poverty, adopt positive coping strategies and experience successful outcomes. This model could be extrapolated to food insecurity. Identifying PDs and the unique but positive coping strategies could help us a) provide culturally acceptable behaviors adopted by PDs, which can be promoted, b) identify motivations of PDs for following such behavior, which can be encouraged, and finally, c) identify key people within the PD families which can be role model for the rest of the food insecure families. Although our study did not identify PDs per se, it did identify strategies which were positive and unique. The common and positive strategies could be used to establish the foundation of an intervention program. The unique and positive strategies could be extrapolated to other countries wherever possible. These strategies included food pantries, freezing food, 
bulk food preparation, pooling resources with other family members or friends, gardening, eating at religious places or institutions and part-time work to increase money to purchase food. These positive unique strategies could be taught to other food insecure families as strategies to be used during food insecure situation.

\section{Conclusions}

Many important conclusions could be made for the study. First, there is high prevalence of food insecurity within our sample. Secondly, households adopt coping strategies as an expression of negotiated decisions to minimize the impact of food insecurity in the households. The strategies which are common could be used as foundation to develop interventions to alleviate hunger and food insecurity. Unique, positive strategies could be used to develop interventions which are culturally appropriate, wherever possible. Finally, the coping experience of respondents portray that food insecurity is manageable process. It could be managed by developing programs based on positive coping strategies observed for resilient and food insecure families.

\section{References}

[1] FAO. Rome declaration on world food security and world food summit plan of action. Rome: FAO. 1996.

[2] FAO, IFAD and WFP. The State of Food Insecurity in the World 2013. The multiple dimensions of food security. Rome, FAO. 2013.

[3] Nord, M. Food insecurity in households with children: Prevalence, severity, and household characteristics. U.S. Department of Agriculture, Economic Research Service, Sep. 2009. Available: www.ers.usda.gov/Publications/EIB56/.

[4] Agarwal, S., Sethi, V., Gupta, P., Jha, M., Agnihotri, A. and Nord, M. Experiential household food insecurity in an urban underserved slum of North India. Food Security, 1, 239-50. Aug 2009.

[5] World Bank. Malnutrition prevalence, height for age (\% of children under 5), 2011. Available: http://data.worldbank.org/indicator/SH.STA.STNT.ZS.

[6] Campbell, C.C. Food insecurity: A nutritional outcome or a predictor variable, Journal of Nutrition, 121, 408-15. 1991.

[7] Black, R.E., Allen, L.H., Bhutta, Z.A., Caulfield, L.E., de-Onis, M., Ezzati, M., Mathers, C., Rivera, J, Maternal and Child Undernutrition Study Group. Maternal and child undernutrition: global and regional exposures and health consequences. Lancet, 371, 243-260. 2008.

[8] Gupta, P., Singh, K., Seth, V., Agarwal,S., Mathur, P. Association of Food Insecurity and Malnutrition among Young Children (6-36 Months). TheIndian Journal of Nutrition and Dietitics, 51 (3). 2014.

[9] Hernandez, D.C., Jacknowitz, A. Transient, but not persistent, adult food insecurity influences toddler development. J Nutr, 139, 1517-24. 2009.

[10] Townsend, M., Peerson, J., Love, B., Achterberg, C., \& Murphy, S. Food Insecurity Is Positively Related to Overweight in Women. $J$ Nutr, 131, 1738-45. 2000.

[11] Jyoti, D., Frongillo, E. \& Jones, S. Food Insecurity Affects School Children's Academic Performance, Weight Gain, and Social Skills. J Nutr, 135, 2831-9. 2005.

[12] Radimer, K.L., Olson, C.M., Greene, J.C., Campbell, C.C. Habicht, J.P. Understanding hunger and developing indicators to assess it in women and children. Journal of Nutrition Education, 24, 36S-45S. 1992.

[13] Mardiharini, M. Family-coping strategies in maintaining welfare during the economic crisis in Indonesia: a case studying rural and urban areas in Bogor, West Java, Indonesia. Journal of Agricultural Economics, 23(1), 53-70. 2005.

[14] Maxwell, D., and Caldwell, R. The Coping Strategies Index: The Field Methods Manual-Second Edition. Atlanta, Medford and Tucson: CARE International, WFP, Feinstein International Center and TANGO International. 2008.

[15] Norhasmah, S., Zalilah, M.S., Mohd Nasir, M.T., Kandiah, M., Asnarulkhadi, A.S. A Qualitative Study on coping strategies among women from food insecurity households in Selangor and Negeri Sembilan. Malays J Nutr, 16(1): 39-54. 2010.

[16] Quisumbing, A.R., Brown, L.R., Feldstein, H.S., Haddad, L., Pena, C. Women: the key to food security. Washington DC, Food Policy Report, the International Food Policy Research Institute. 1995.

[17] Blumberg, S.J., Bialostosky, K., Hamilton, W.L., Briefel, R.R. The effectiveness of a short form of the Household Food Security Scale. American Journal of Public Health, 89, 1231-123. 1999.

[18] US Department of Agriculture. U.S. Household Food Security Survey Module: Six-Item Short Form. Economic and Research Service, US Department of Agriculture, Washington DC. 2008.

[19] Aronson, J. A pragmatic view of thematic analysis. The Qualitative Report (1), 1994. Available: http://www.nova.edu/sssOR/BackIssues/QR2-1/aronson.html.

[20] Braun, V., Clarke, V. Using thematic analysis in psychology. Qualitative Res Psychol, 3, 77-10. 2006.

[21] Kempson, K., Keenan, D.P., Sadani, P.S., Adler, A. Maintaining food sufficiency: Coping strategies identified by limited-resources individuals versus nutrition educators. J Nutr Educ Behav, 35, 179-88. 2003.

[22] Dore, A.R., Adair, L.S., Popkin, B.M. Low income Russian families adopt effective behavioral strategies to maintain dietary stability in times of economic crisis. J Nutr, 133, 3469-75. 2003.

[23] Corbett, J. Famine and household coping strategies. World Dev, 16, 1099-112. 1988.

[24] Kabeer, N. Women, household food security and coping strategies. Institute of Development Studies. Nutrition Policy Discussion Paper (UN/ACC) No: 6. Geneva, Switzerland. 1990.

[25] Castaneda, C.Q., Bacos, F.F., Zarate, R.U., Galang, M.R., Molano, W.L. Coping behavior towards food security of households in marginalized Philippine communities. Food and Research Institute, Science and Technology Project: Poster Presentation. Republic of Philippines, 2000. Available: http://wwwl.fnri.dost.gov.ph/posters/streetfood.pdf.

[26] Shariff, Z.M., Khor, G.L. Household food insecurity and coping strategies in a poor rural community in Malaysia. Nutrition Research and Practice, 2(1), 26-34. 2008.

[27] Studdert, L.J., Frongillo, E.A. Valois, P. Household food insecurity was prevalent in Java during Indonesia's economic crisis. J Nutr, 131, 2685-91. 2001.

[28] Agbola, P.O. Analysis of food insecurity coping strategies among farming households in Osun area of southwestern Nigeria. J Agricult Forestry, 6(2). 2008.

[29] Oxfam International and Save the Children. Rising food prices in the Sahel: The urgency of long-term action, Briefing Note. Oxfam International and Save the Children. Africa. 2008.

[30] FAO. The state of food insecurity in the world. High food prices and food security - threats and opportunities. Rome: FAO. 2008.

[31] Banik, D. Starvation and India's Democracy. $1^{\text {st }}$ ed. London \& New York: Routledge. 2007.

[32] Popkin-Barry M., Adair, L.S., Ng, S.W. Global nutrition transition and the pandemic of obesity in developing countries. Nutrition Reviews, 70(1), 3-21. 2012.

[33] Bruening, M., MacLehose, R., Loth, K., Story, M., and NeumarkSztainer., D. Feeding a Family in a Recession: Food Insecurity among Minnesota Parents. American Journal of Public Health, 102(3), 520-6. March 2012.

[34] Wishik, S.M., Van der Vynkt, S. The use of nutritional positive deviants' to identify approaches for modification of dietary practices. American Journal of Public Health, 66, 38-42. 1976. 